\title{
Perspectivas de las comunidades en torno al contexto de vulnerabilidad en que vive la juventud en la RACS
}

\author{
Ethel Martínez Webster \\ Consultora
}

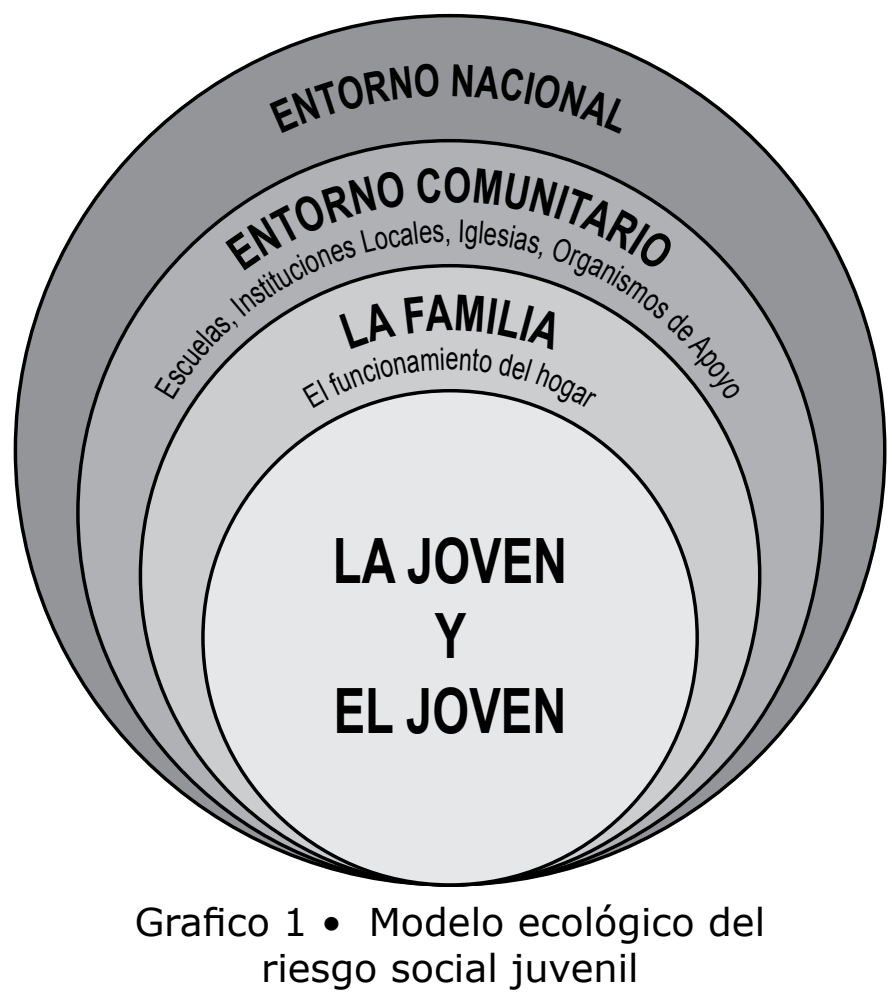

Este artículo presenta los resultados más significativos obtenidos de 36 grupos focales y 23 entrevistas, realizadas como parte del estudio "Situación socio-educativa y económica de la juventud en contexto de vulnerabilidad en cinco municipios de la RAAS"1.

El estudio cubrió 20 comunidades entre urbanas y rurales de los municipios de Bluefields, Corn Island, Desembocadura de la Cruz de Río Grande, Kukra Hill y Laguna de Perlas. Los grupos focales estuvieron integrados por docentes, líderes comunales, padres y madres de familia, y jóvenes entre las edades de quince a veinticuatro años. Las entrevistas fueron hechas con autoridades locales y otras personas de reconocida influencia en cada comunidad.

Siguiendo el modelo de análisis ecológico (Gráfico 1), las opiniones de los entrevistados y de los participantes en los grupos focales sobre los factores que influyen para que adolescentes y jóvenes abandonen la escuela y se integren a las pandillas, se ubicarons en cuatro ámbitos: (1) el joven tal y como se ha formado con sus fortalezas y debilidades reflejadas en su comportamiento; (2) la familia a que pertenece cada joven y el funcionamiento del hogar; (3) el entorno comunitario en donde están ubicadas la escuela, las instituciones locales, las iglesias y los organismos de apoyo, (4) y el entorno nacional y global que también es determinante en la vida de la población.

\section{El joven y la joven}

Tanto docentes, como padres, madres y líderes coinciden en que las principales causas del abandono escolar juvenil son: el desinterés por el estudio, la falta de un plan de vida, la búsqueda de su identidad, la violencia y mala comunicación con padres y madres. Todos estos factores les mueven a unirse a otros grupos de jóvenes que están en su misma situación, y en cuya compañía sienten comprensión y aceptación; hasta optan por dejar la escuela, por ser un sitio en donde se les juzga y cuestiona por su comportamiento. 


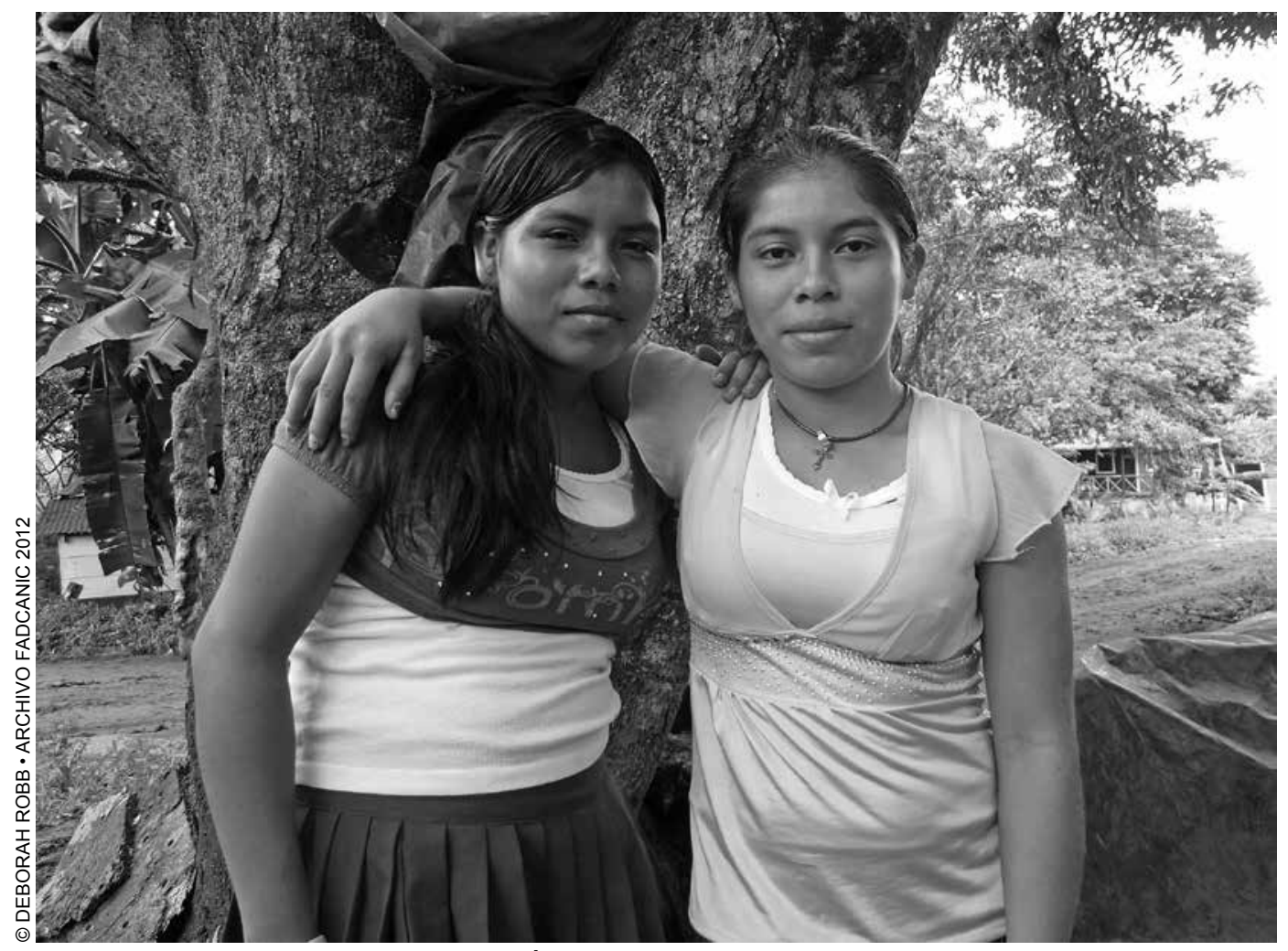

Estudiantes del Centro de Educación Ambiental y Agroforestal de FADCANIC.

Los integrantes de los grupos focales y los entrevistados identifican los embarazos tempranos y el abandono de la pareja, como causas del abandono escolar. Pero no delimitan si es porque la joven ya no puede seguir estudiando o bien porque es expulsada de la escuela. También el consumo de drogas y alcohol lo perciben como causa del abandono escolar.

Es importante destacar que, de forma general, los diferentes grupos focales identifican que la comunicación entre jóvenes y sus progenitores es limitada o no existe. Algunos grupos focales también enfatizan que hay comunidades donde la juventud es sana, pero en alta situación de riesgo, porque solamente pueden cursar educación primaria ya que no hay otras opciones de estudio para continuar formándose. También afirman que no hay interés de las autoridades para apoyar a la juventud y darle oportunidad de formarse como líderes.

Los padres y madres de familia agregan además que la juventud hace uso indebido de la tecnología y que una buena cantidad de muchachas se dedican a la prostitución. Esta afirmación revela que no distinguen entre prostitución y explotación sexual comercial, porque la generalizan a todos los grupos de edad.
Otros problemas que los grupos focales identifican en los jóvenes, como limitantes del estudio, son la falta de recursos económicos y bajos valores morales. En conclusión, prevalece una visión de la juventud como problema y una percepción generalizada de la falta de oportunidades para la continuidad de la educación secundaria y el desinterés de las autoridades para cambiar esta situación.

\section{La Familia}

Desde la perspectiva del personal docente se identifica una influencia negativa de la familia hacia la niñez y la juventud, cuando la familia vende drogas o está vinculada con este negocio y cuando padres y madres consumen alcohol. En este tipo de familia generalmente no se muestra afecto e interés hacia sus vástagos, más bien son desvalorizados y menospreciados. Falta comunicación, comprensión y confianza en las familias, teniendo como resultado los conflictos y las malas relaciones entre padres e hijos. Estos son factores que llevan a adolescentes y jóvenes a tomar actitudes que no les favorecen. En el caso de Sandy Bay, Kara y Karawala, según expresión de los grupos focales de docentes, la comunicación familiar se da solamente entre $1 \%$ a $2 \%$ de la población estudiantil que se atiende. 
La mayoría planteó como razones de las malas relaciones y falta de comunicación entre los miembros de la familia, las siguientes apreciaciones:

- Violencia intrafamiliar.

- Influencia de la TV y la música vulgar que les provoca reacciones de violencia.

- Los padres se dedican más al trabajo.

- No hay confianza entre progenitores e hijos.

- La casa es un expendio de drogas.

- El ambiente socioeconómico y cultural en que funciona la familia no es el adecuado.

- Falta de valores espirituales en los hogares.

También se identifica que las condiciones económicas colocan en situación de riesgo a la juventud, sobre todo cuando éstas tienen que trabajar, en vez de estudiar, para apoyar con la manutención de la familia o quedan solos cuidando la casa y a sus hermanos menores, mientras sus padres y madres van en busca de trabajo en el extranjero. También hay niños y niñas trabajadores, niñas y niños huérfanos y jóvenes que se sienten abandonados o que realmente lo están.

Se identifica también despreocupación de padres, madres y tutores, sobre el avance escolar de sus hijos e hijas. Esta despreocupación se refleja en la inasistencia a las reuniones de la escuela, la falta de apoyo de padres y madres en las tareas escolares, una desvalorización del estudio, la no orientación a jóvenes en torno a su futuro, además de la escasa motivación para estudiar en las mismas escuelas.

Padres y madres de familia coinciden con docentes al afirmar que por escasos recursos económicos adolescentes y jóvenes no van a la escuela o la abandonan para trabajar. Estos progenitores también culpan a su prole revelando la tendencia adultista de culpar a la niñez y la juventud por la situación en que viven, no asumiendo su responsabilidad parental. Según estos progenitores:

- Hay mucha vagancia entre muchos jóvenes.

- Los jóvenes dejan todo el trabajo a los padres.

- Cualquier tropiezo que tienen los jóvenes en sus vidas culpan a sus padres.

- No les gusta que sus padres les corrijan.

- Los jóvenes no tienen comunicación con sus padres.
Sobre los trabajos que realizan adolescentes y jóvenes en la familia, los progenitores en su mayoría expresaron que las mujeres ayudan en los trabajos domésticos y los hombres realizan trabajo de campo, lo que va afianzando las diferencias de género al transmitir roles diferenciados.

A pesar de que el personal docente afirma que los padres y las madres no se comunican con sus descendientes, éstos últimos refieren que sí conversan y se enfocan, principalmente, en el peligro de las drogas, embarazos en la adolescencia, salud sexual y reproductiva, noviazgo, educación —que estudien y se preparen— higiene personal y cómo comportarse en el trabajo. Pero las actitudes de sus hijos en estas conversaciones son más bien evasivas, rebeldes y de oposición. Para algunos padres y madres, la juventud se siente autosuficiente y reticente por la influencia de la televisión. De nuevo, no hay una valoración de su influencia como padres y madres en la formación de los hijos.

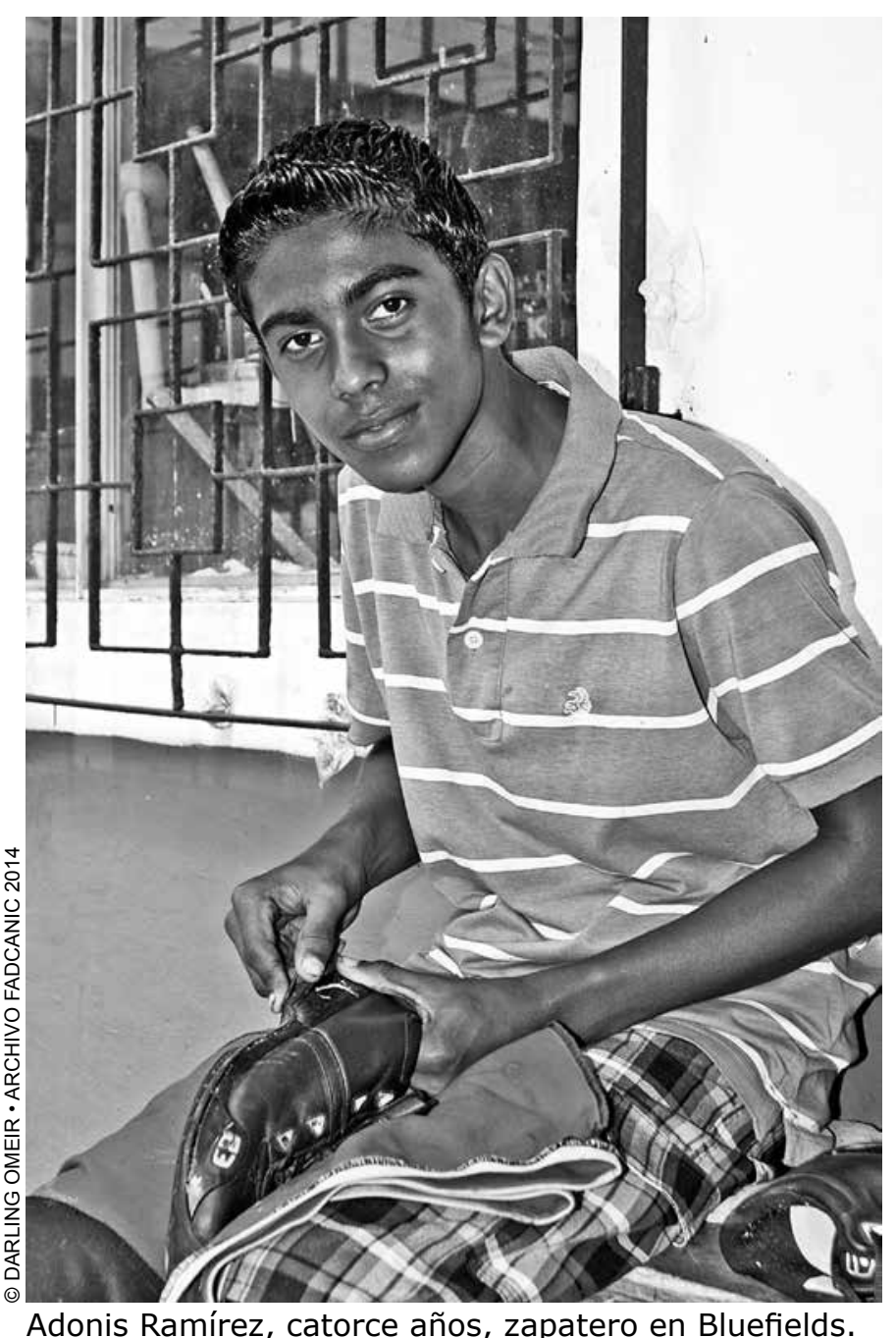


Respecto a los métodos de corrección refieren que utilizan el consejo, hablándoles de la mejor manera, poniéndoles ejemplos (de otros), brindando amor y afecto, dando la oportunidad de educarse y guiándolos espiritualmente.

En ningún momento se mencionó el castigo físico y los gritos como métodos de corrección, a pesar de que esto sí fue mencionado en las encuestas a jóvenes. Esto también se deja entrever cuando se les preguntó por las reacciones de la juventud ante las medidas de corrección; algunos refirieron que: (...) "ya no podemos regañarlos porque nos agreden", (...) "se amparan en la ley de menores y se atreven a llamar a la policía cuando se les reprende". Esto quiere decir que aunque no lo acepten, sí utilizan el castigo físico y verbal para corregir.

Además utilizan la oportunidad de asistir a una escuela de formación como forma de corrección y aislamiento - asistir a la escuela de Wawashang fue mencionado como una opción de corrección en los municipios de Bluefields, Corn Island, Pearl Lagoon y Desembocaduralo cual no contribuye en su desarrollo personal y en el aprovechamiento que se tenga de dichos estudios.

\section{El entorno comunitario}

Sobre el entorno comunitario, docentes participantes de los grupos focales destacaron como factor de riesgo en la juventud la contradicción entre lo que se enseña en la escuela y lo que se practica en el hogar, por lo tanto, ambas esferas pierden todo atractivo y la socialización en el grupo de pares resulta ser el sustituto de ambos.

Destacan, así mismo, que la falta de calidad en la enseñanza, que va desde el aburrimiento hasta el maltrato del estudiantado, hace que a los grupos de pares (grupo juvenil, pandilla, grupo de interés) les resulte un ambiente colectivamente más atractivo.

La pobreza y los problemas económicos de la comunidad, también son identificados como factores que propician el abandono escolar, señalizándose además que la juventud en edad laboral no trabaja porque hay pocas oportunidades de trabajo. Señalan la falta de empleo en el entorno comunitario como un factor negativo para la juventud.

El personal docente también plantea que en algunos municipios no existen instituciones que apoyen a la

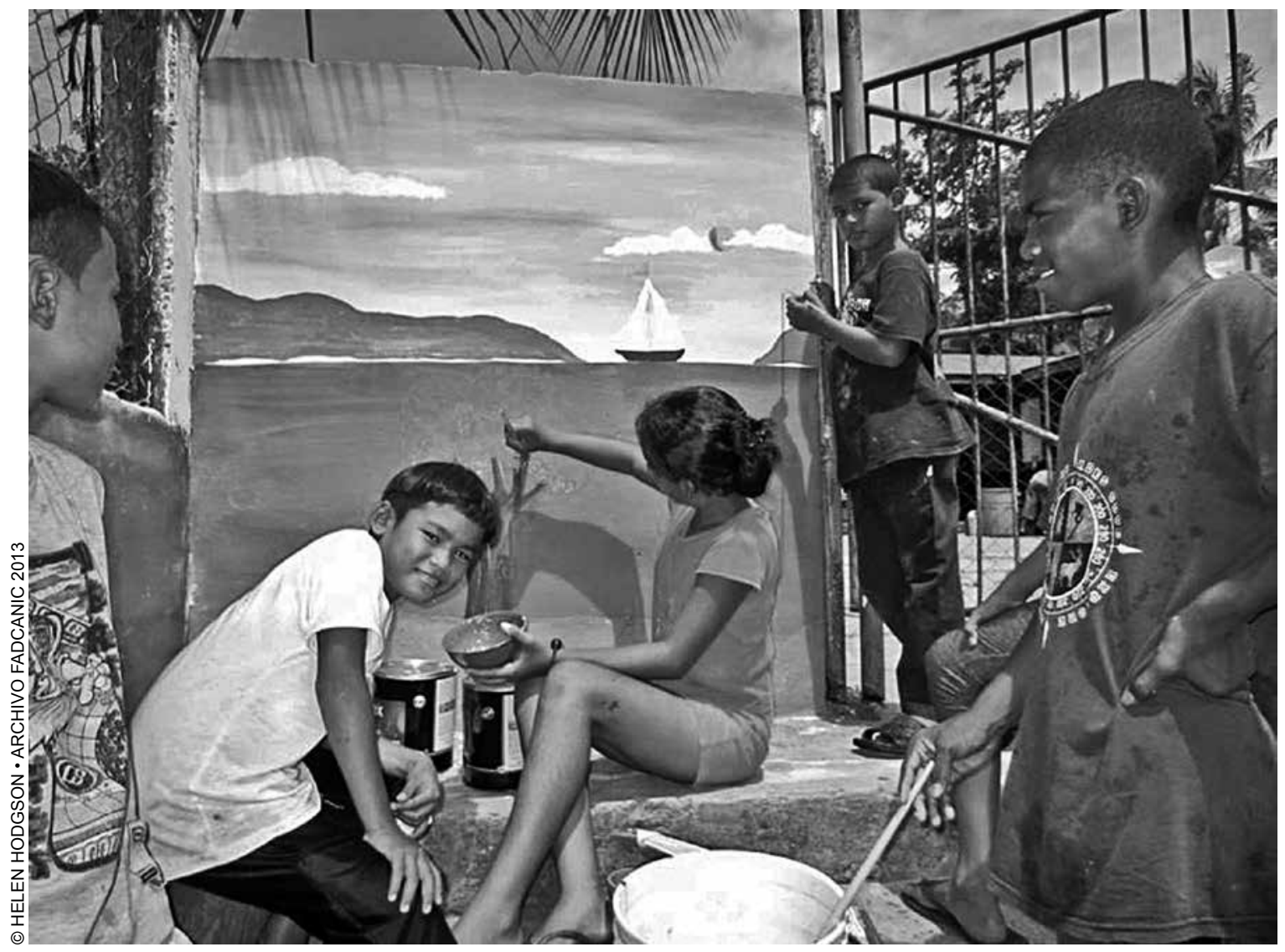

Aprendiendo a pintar murales en El Bluff. 
juventud en situación de riesgo y que no hay oportunidades de estudio, ni proyectos educativos dirigidos a jóvenes en situación de riesgo, faltando la atención a niños, niñas, adolescentes y jóvenes en situación de extra edad.

En la percepción de los y las entrevistadas, las actividades deportivas y culturales, los estadios de balompié y beisbol, los deportes y gimnasios son las principales posibilidades de recreación y distracción que existen en los municipios. Pero expresaron que la niñez y la juventud cuentan con pocos espacios para practicar estos deportes. Señalan además que estos deportes son promocionados como deportes "de hombres", limitando la recreación en las mujeres jóvenes.

En las entrevistas se visibilizan algunos programas que se han implementado en Bluefields, Corn Island, Pearl Lagoon y Kukra Hill, siendo la mención más frecuente la capacitación en salud sexual y reproductiva. Así también, en los municipios de Desembocadura, Corn Island y Kukra Hill, las actividades deportivas destacan entre los principales programas mencionados por los entrevistados. En las entrevistas efectuadas en los municipios de Desembocadura y Kukra Hill, un porcentaje significativo se refirió asimismo a los programas de intercambio de experiencia de jóvenes entre municipios. En el municipio de Desembocadura expresaron que las iglesias y los coros son otras posibilidades de recreación y distracción.

Como sucede con progenitores, el liderazgo comunitario reconoce que el diálogo intergeneracional es limitado pero culpan a la juventud. Líderes de ambos sexos no perciben la falta de espacios de participación y de diálogo con autoridades. Da la impresión que lo que esperan de la juventud es la adopción de actitudes pasivas y la aceptación, sin cuestionamiento, de las orientaciones y consejos de sus mayores. Se percibe, entretanto, que la juventud carece de credibilidad ante las personas adultas y viceversa, o sea, que la sociedad condiciona las conductas que asume la juventud. Pero esto no es reconocido por las personas adultas.

La valoración que se hace de las organizaciones municipales de la juventud y su contribución a mejorar la situación de los adolescentes y jóvenes en situación de riesgo es ambigua. Por un lado identifican organizaciones que trabajan con jóvenes, pero por otro, no identifican ni reconocen ninguna organización juvenil propia del municipio. A nivel regional fueron identificadas, entre otras, las organizaciones no gubernamentales ACRIC, CEDHECA y FADCANIC. Entre las instituciones gubernamentales fueron identificadas el MINED, MINSA, alcaldías y el Programa Voz Joven que desarrolla trabajo con jóvenes. Respecto a las organizaciones políticas, éstas no son visibilizadas como parte de la solución y más bien se les hace un llamado a definir programas para jóvenes en riesgo.

Sobre la responsabilidad política, sociocultural y económica de las alcaldías municipales y el gobierno regional para con la juventud en situación de riesgo, la mayoría de docentes expresó que ninguna de estas dos instancias está cumpliendo con esta misión, aunque, por ejemplo expresaron que:

\section{(..) Estos tienen que trabajar juntos para un buen progreso, ayudar a los jóvenes en donaciones, becas y realizar actividades culturales, ya que éstos son el futuro de la comunidad.}

\section{Entorno nacional}

Quienes practican la docencia plantearon que no se ve preocupación, por parte del Estado, para establecer control sobre los actos de violencia propios de agrupaciones juveniles que comienzan a perfilar en algunas comunidades. Reiteran también la falta de proyectos educativos dirigidos a jóvenes en situación de riesgo.

\section{Acciones ante las situaciones de vulnerabilidad de la juventud en riesgo}

Las acciones que impulsa el personal docente una vez que identifican a jóvenes con actitudes de rebeldía y desadaptación social es comunicarlas a la dirección del centro de estudios. En la mayoría de los casos involucran a los progenitores. En los casos más graves, los centros educativos urbanos utilizan a psicólogos, cuando los tienen. Unos pocos refieren los casos de jóvenes al Centro de Atención Psicosocial en Bluefields (CAPS).

Respecto a la reinserción de jóvenes con estos problemas, el personal docente considera que es mejor tratar primero con los progenitores de la familia y luego con las diferentes instancias, para alcanzar un consenso en torno a la ayuda a prestar para evitar que los padres impongan medidas de castigo que, lejos de contribuir a su reinserción, los impulse más a continuar en conductas de riesgo. Recomiendan un trabajo en cadena padres-estudiantes. 


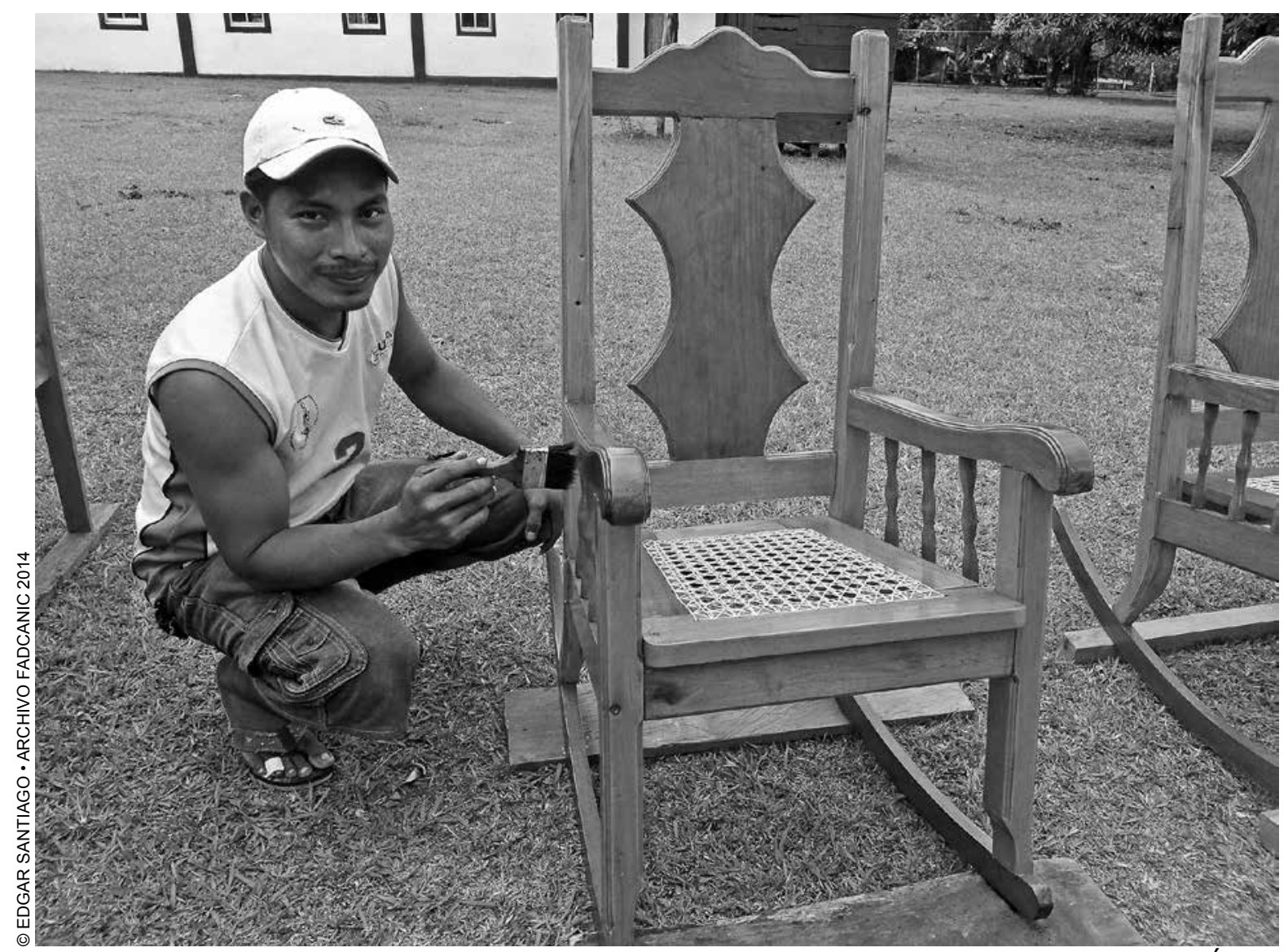

Bernardino Demetrio, veinticuatro años, egresado del curso de carpintería y ebanistería de EduÉxito.

Sobre la atención a la niñez, adolescencia y juventud en edad escolar que se encuentran en situación de riesgo y exclusión social, los diversos grupos focales tienen algunas opiniones similares cuando se refieren a cómo hacer para que la juventud estudie y se prepare para la vida. Sus propuestas van encaminadas a la promoción de valores, detección temprana de trastornos psico-afectivos y referencia a especialistas, visitas casa a casa, promoción del deporte y construcción de centros recreativos; además aconsejan la promoción de incentivos, diversas motivaciones, consejos, ser más amigos y susceptibles con este segmento de la juventud, gestionar y ofrecerles becas.

Algunos docentes sugieren acciones propiamente escolares tales como organizar a grupos de docentes y darles charlas para luego impartirlas al estudiantado. También creen necesario que el estudiantado cumpla las normativas de los centros. Proponen que se atienda con urgencia a estudiantes extra edad y que se promuevan carreras técnicas para que la juventud pueda estudiar y trabajar.
Tanto en Bluefields, como en Pearl Lagoon y Kukra Hill, los progenitores consideran que generar confianza con los hijos y procurarles una buena educación es una alternativa para orientarlos a una vida saludable y exitosa. En Corn Island, Pearl Lagoon y Desembocadura, los padres también consideran que debe capacitarse a la juventud para el trabajo ya sea en el campo o en los negocios.

Las áreas para la formación técnica que fueron identificadas en los grupos focales con adultos, adolescentes y jóvenes llegan a variar entre sí, aunque de forma general las preferencias de la juventud se ven reflejadas también en las de las personas adultas. Para un elenco de las propuestas de carreras técnicas que emergieron del estudio, ver las Tablas 9 sobre las "Áreas técnicas más demandadas por adolescentes y jóvenes" y 10 relativa a las "Oportunidades laborales identificadas por actores claves"2 en el artículo Vulnerabilidad socioeducativa y económica de adolescentes y jóvenes en cinco municipios de la RACS de esta edición de Wani. 